\title{
Analisis Pelaksanaan Program Pendidikan Nonformal Bagi Anak Jalanan
}

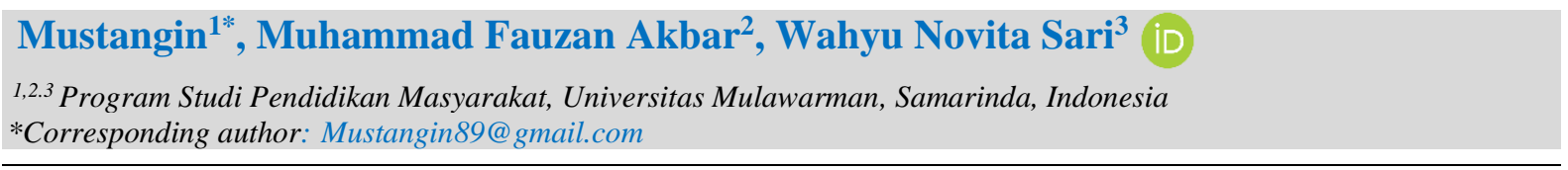

\begin{abstract}
Abstrak
Pendidikan nonformal merupakan pendidikan berbasis kebutuhan dan disesuaikan dengan karakteristik anak jalanan. Penelitian ini bertujuan untuk menganalisis pelaksanaan pendidikan nonformal bagi anak jalanan. Metode penelitian yang digunakan dalam penelitian ini adalah penelitian kualitatif untuk mendapatkan data lebih spesifik dan lebih mendalam mengenai pendidikan nonformal bagi anak jalanan. Teknik penelitian pada penelitian ini adalah menggunakan teknik wawancara, observasi dan studi dokumen dengan teknik analisis datanya adalah reduksi data, penyajian data dan penarikan kesimpulan. Hasil penelitian menunjukkan bahwa proses pendidikan untuk anak jalanan yang dilaksanakan bertempat di sekitar jalanan karena pendidikan nonformal bersifat fleksibel sesuai dengan kondisi dari anak jalanan itu sendiri dan disesuaikan dengan kontrak belajar yang telah disepakati. Hal itu dikarenakan anak jalanan sendiri memiliki kesibukan sehingga fasilitator bisa menyesuaikan dengan kondisi anak jalanan. Evaluasi oleh fasilitator sebagai tenaga pengajar anak jalanan juga dilakukan untuk mengetahui tingkat keberhasilan pelaksanaan pendidikan nonformal dan bahan masukan untuk pengembangan program. Berdasarkan hasil penelitian, dapat disimpulkan bahwa pendidikan nonformal yang dilaksanakan untuk anak jalanan diantaranya adalah pendidikan dasar berupa pendidikan untuk menuntaskan buta aksara meliputi kegiatan membaca, menulis, dan berhitung (calistung) sebagai pendidikan dasar bagi anak jalanan. Selain itu pendidikan keterampilan hidup juga diajarkan untuk membekali anak jalanan keterampilan yang dapat digunakan untuk mengembangkan kapasitasnya sehinga dari adanya pendidikan keterampilan ini dapat menjadikan anak jalanan memiliki kapasitas sehingga anak jalanan tidak kembali lagi ke jalan.
\end{abstract}

Kata Kunci: Anak Jalanan, Evaluasi, Pendidikan Nonformal

\section{Abstract}

Non-formal education is education based on needs and adapted to the characteristics of street children. This study aims to analyze the implementation of non-formal education for street children. The research method used in this study is qualitative research to obtain more specific and in-depth data on non-formal education for street children. The research technique in this research is using interview, observation, and document study techniques with data analysis techniques are data reduction, data presentation, and conclusion drawing. The results showed that the education process for street children was carried out around the streets because non-formal education was flexible according to the conditions of the street children themselves and adapted to the agreed learning contract. This is because street children themselves are busy so that the facilitator can adjust to the conditions of street children. Evaluation by the facilitator as a street child teacher is also carried out to determine the success rate of non-formal education implementation and input materials for program development. Based on the results of the study, it can be concluded that non-formal education carried out for street children includes basic education in the form of education to complete illiteracy including reading, writing, and counting activities (calistung) as basic education for street children. In addition, life skills education is also taught to provide street children with skills that can be used to develop their capacity so that this skill education can make street children have the capacity so that street children do not return to the streets.

Keywords: Street Children, Evaluation, Non-formal Education

\section{INTRODUCTION}

Permasalahan kemiskinan merupakan salah satu permasalahan yang menjadi salah satu perhatian untuk diselesaikan. Salah satu komunitas dari masyarakat ini adalah komunitas anak jalanan yang sering ditemui di jalanan besar di kota-kota besar yang ada di Indonesia. Anak

$\begin{array}{ll}\text { History: } & \\ \text { Received } & \text { : July 10, } 2021 \\ \text { Revised } & \text { : July 12, } 2021 \\ \text { Accepted } & \text { : August 13, } 2021 \\ \text { Published } & \text { : August 25, } 2021\end{array}$


jalanan berbeda dengan anak lain pada umumnya, kehidupan anak jalanan dapat kita lihat dari kesehariannya yang melelahkan, kotor, dan bisa dikatakan kehidupannya keras (Melindra \& Irmawita, 2020; Setiawan et al., 2016; Ummatin, 2020). Keberadaan anak jalanan seperti yang telah diuraikan sebelumnya bahwa anak jalanan menjadikan jalanan sebagai salah satu tempat untuk memenuhi kebutuhan sehari-hari. Anak jalanan berada dalam keluarga yang memiliki permasalahan kemiskinan. Anak jalanan yang ada saat ini berusaha membantu perekonomian keluarga bahkan upaya mereka bertahan hidup dengan melakukan pekerjaan seperti berjualan koran, berdagang asongan di jalan, tukang semir sepatu, pengamen dan lainlain. Keberadaan anak jalanan bukan tanpa alasan, banyak dari anak-anak jalanan yang hidup sebagai komunitas masyarakat miskin yang memaksa anak jalanan harus bekerja guna membantu perekonomian keluarga bahkan untuk dapat bertahan hidup. Ada berbagai faktor anak menjadi anak jalanan diantaranya adalah faktor kemiskinan atau perekonomian keluarga yang sulit. Masalah anak jalanan berawal dari kondisi ekonomi orang tua yang miskin sehingga tidak mampu menunjang seluruh kebutuhan keluarga (Masdin \& Mulu, 2017; Sukmaningrum \& Faizah, 2019). Faktor kemiskinan menjadikan anak-anak turun ke jalan untuk bekerja untuk bekerja membantu orang tuanya dalam memenuhi kebutuhan yang masih kurang. Anak jalanan tidak dapat membantu keluarganya jika harus memilih untuk bersekolah. Alasan inilah menjadikan anak jalanan tidak memiliki kesempatan untuk mengenyam pendidikan. Selain itu, banyaknya anak jalanan yang tidak bisa mendapatkan pendidikan formal di sekolah cenderung disebabkan oleh praktik diskriminasi yang dilakukan pihak sekolah terhadap mereka (Herlina, 2014). Sedangkan pendidikan menjadi salah satu upaya untuk meningkatkan kapasitas seseorang untuk dapat berperan dalam rangka pembangunan.

Ada banyak tantangan yang dihadapi oleh anak jalanan dalam mendapatkan pendidikan. Kondisi anak jalanan yang telah diuraikan diatas menjadi salah satu tantangan untuk menyediakan layanan pendidikan yang sesuai dengan kondisi dan kebutuhan pendidikan anak jalanan itu sendiri. Untuk mengatasi tantangan tersebut diperlukan pendidikan yang fleksibel untuk mempermudah anak jalanan mendapatkan pendidikan. Tugas utama pendidikan nonformal adalah sebagai komplemen atau pelengkap, pengganti, dan penambah pendidikan formal, terutama bagi masyarakat yang ingin menambah pengetahuan selain yang didapatkan dari sekolah formal, drop out, atau bahkan yang tidak pernah bersekolah sama sekali (Arnady \& Prasetyo, 2016; Rizka \& Hardiansyah, 2016). Salah satu penyelenggaraan pendidikan untuk dapat mengatasi permasalahan ini adalah pendidikan nonformal. Berbeda dengan pendidikan formal, pendidikan nonformal lebih fleksibel sehingga memudahkan anak jalanan untuk mendapatkan pendidikan. Pentingnya pendidikan nonformal ini yaitu sebagai wadah pendidikan nonformal ini membantu menyediakan bantuan untuk warga belajar yang mengalami kesulitan belajar dan berusahan meningkatkan motivasi belajar warga belajar melalui kelompok belajar (Safitri, 2017). Pendidikan nonformal sangat dibutuhkan saat ini dan masa depan, karena termasuk bagian dari sistem pendidikan yang tidak ekslusif dan dapat menjangkau setiap lapisan masyarakat yang tidak terlayani oleh pendidikan formal (Muslim \& Suci, 2020).

Beberapa penelitian yang sejalan dengan penelitian ini seperti yang dilakukan oleh (Elian \& Ilyas, 2020) yang menyatakan bahwa tahapan kegiatan pada penelitian tersebut sudah sesuai dengan teori pelaksanaan metode pembelajaran partisipatif dan hasil pembelajaran berupa teknik/skill baru dalam bermain alat musik. Kemudian penelitian yang dilakukan oleh (Hermawan \& Suryono, 2016) yang menyatakan bahwa strategi pengembangan partisipasi masyarakat dalam penyelenggaran program-program PKBM Ngudi Kapinteran, Semanu, Gunungkidul yaitu dengan komunikasi, keterlibatan masyarakat dan pemberdayaan komunitas. Penelitian ini bertujuan untuk menganalisis pelaksanaan pendidikan nonformal bagi anak jalanan di Klinik Jalanan Samarinda. 


\section{MATERIALS AND METHODS}

Penelitian ini merupakan penelitian dengan menggunakan pendekatan penelitian kualitatif. Penelitian kualitatif pada penelitian ini dipilih karena sama dengan tujuan penelitian yaitu menganalisis terkait dengan pelaksanaan pendidikan nonformal bagi anak jalanan di Klinik Jalanan Samarinda. Adanya pendekatan penelitian kualitatif tersebut maka akan di dapat data yang rinci tentang pelaksanaan program pendidikan nonformal di Klinik Jalanan Samarinda. Metode penelitian yang digunakan dalam penelitian pelaksanaan program pendidikan nonformal di Klinik Jalanan Samarinda menggunakan metode deskriptif. Metode penelitian deskriptif ini dikarenakan pada penelitian ini akan mendeskripsikan secara lebih detail dan rinci tentang bagaimana proses pelaksanaan pendidikan nonformal di Klinik Jalanan Samarinda.

Proses penelitian dilaksanakan dengan proses pengumpulan data di lapangan, oleh karena itu pada pengumpulan data pada penelitian terkait dengan proses pelaksanaan pendidikan nonformal bagi anak jalanan ini menggunakan teknik pengumpulan data sesuai dengan pendekatan penelitian yang telah ditentukan sebelumnya. Adapun teknik pengumpulan data yang dilaksanakan dalam penelitian ini meliputi wawancara, observasi, dan studi dokumen untuk mendapatkan data di lapangan. Data yang telah dikumpulkan melalui berbagai teknik penelitian yang dipilih oleh peneliti, selanjutnya data tersebut dianalisis. Pada penelitian ini analisis data yang digunakan mengadopsi teknik analisis data yang ditulis oleh Milles dan Huberman yaitu tiga teknik analisis data diantaranya reduksi data, penyajian data, dan penarikan kesimpulan (Sugiyono, 2016).

\section{RESULTS AND DISCUSSION}

\section{Hasil}

\section{Program Pendidikan Nonformal bagi anak jalanan di Klinik Jalanan Samarinda}

Program pendidikan nonformal yang dilaksanakan oleh Klinik Jalanan Samarinda bagi anak jalanan adalah pendidikan dasar seperti pembelajaran baca tulis dan berhitung (Calistung). Pembelajaran Baca, Tulis dan Berhitung (Calistung) merupakan pendidikan dasar yang harus dimiliki oleh setiap individu termasuk juga anak jalanan. Literasi adalah kemampuan membaca dan menulis terdapat investasi di dalamnya yang mengarah pada pembangunan nasional (Olomukoro \& Adelore, 2015). Keterampilan menulis, membaca dan berhitung merupakan keterampilan dasar yang harus dimiliki setiap manusia dan tidak dapat dipisahkan dalam kehidupan manusia. Kemampuan literasi (kemampuan baca tulis dan menghitung) fungsional yang dimiliki oleh masyarakat memiliki pengaruh dalam kehidupannya, hal ini diwujudkan dengan adanya peningkatan rasa percaya diri dalam mengikuti kegiatan sosial dan ekonomi dibandingkan dengan masyarakat yang tidak memiliki kemampuan literasi (Kolawole \& Pusoetsile, 2021). Pentingnya kemampuan dasar literasi bagi masyarakat khususnya anak jalanan adalah anak jalanan dapat berpartisipasi dalam kegiatan sosial bahkan kegiatan ekonomi. Anak jalanan yang memiliki kemampuan literasi akan semakin diterima dalam pergaulan sosial masyarakat. Klinik Jalanan Samarinda sebagai salah satu layanan pendidikan nonformal memiliki fokus untuk memberikan pendidikan dasar bagi anak jalanan agar memiliki kecakapan dasar (membaca, menulis, dan berhitung). Selain program baca, tulis, dan berhitung telah dikuasai oleh anak jalanan yang menjadi warga belajar di Klinik Jalanan Samarinda memberikan program pendidikan nonformal melalui peningkatan keterampilan bagi anak jalanan agar anak jalanan tidak lagi turun ke jalan.

Pendidikan nonformal memiliki banyak ragam dan memiliki tujuan untuk mengembangkan keterampilan atau menambah keterampilan seseorang yang tidak didapatkan di bangku sekolah formal (Dani, Mundzir \& Hardika 2018). Salah satu program pendidikan nonformal adalah pelatihan keterampilan hidup (life skill) bagi anak jalanan 
sehingga anak jalanan memiliki bekal untuk melanjutkan kehidupannya tanpa turun ke jalan lagi. Upaya penanganan anak jalanan salah satunya adalah pemenuhan keperluan yang dibutuhkan ditambah dengan mengajarkan keterampilan (Anandar \& Wibowo, 2015). Upaya penagangan anak jalanan adalah dengan memberikan anak-anak kesempatan menjalani kehidupan yang lebih baik, sehat, aman, dan produktif melalui program-program pembelajaran dan mengorganisir kegiatan-kegiatan konkret yang bergerak di bidang pendidikan, pelayanan kesehatan, pelatihan keterampilan dan kerja sosial dengan komunitas miskin dan terpinggir (Anandar, Whibawa, \& Wibowo, 2015). Pendidikan keterampilan diberikan untuk membekali anak jalanan, strategi mempertahankan hidup di jalanan sehingga pendidikan keterampilan hidup sangat penting diberikan (Rochimah, 2016).

Program pelatihan keterampilan bagi anak jalanan ini merupakan langkah tindak lanjut atau pengembangan program dari program sebelumnya yaitu program baca, tulis, dan hitung yang tujuannya adalah peningkatan keterampilan bagi anak jalanan untuk dapat hidup mandiri dengan penguasaan keterampilan yang telah dimiliki. Pelatihan keterampilan yang diberikan kepada anak jalanan merupakan bentuk dukungan berupa kegiatan pembinaan yang dapat membantu anak jalanan mengembangkan potensi diri karena dengan adanya pelatihan keterampilan bagi anak jalanan diharapkan anak jalanan dapat menghidupi dirinya sendiri dengan kegiatan yang produktif sehingga anak jalan dapat melepaskan diri dari kehidupan mengais di jalanan. Oleh karena itu program pendidikan nonformal yang dilaksanakan di Klinik Jalanan Samarinda mampu memberikan pengetahuan dan keterampilan peserta didiknya sehingga kemampuan peserta didik dapat tereksplor dengan baik.

\section{Pelaksanaan Program Pendidikan Nonformal Bagi Anak Jalanan di Klinik Jalanan Samarinda}

Pelaksanaan pendidikan nonformal merupakan proses pembelajaran yang diselenggarakan di luar sistem pendidikan formal, meskipun dalam pelaksanaannya terkadang menggunakan kurikulum seperti pendidikan formal namun tetap kurikulum yang digunakan khusus kurikulum pendidikan nonformal. Hal tersebut dikarenakan Pendidikan Nonformal merupakan pelengkap, pengganti, dan penambah dari pendidikan formal. Pada pelaksanaannya, pendidikan nonformal dilaksanakan lebih fleksibel sehingga proses pendidikan nonformal ini dapat menjangkau semua lapisan masyarakat yang membutuhkan peningkatan kapasitas melalui program pendidikan. Pendidikan nonformal memang mengalami perubahan, walaupun istilah yang digunakan mengalami beberapa perubahan, secara garis besar fungsi pendidikan nonformal tetap sama yaitu sebagai pelengkap, dan pengganti pendidikan formal bagi warga belajar yang membutuhkan pendidikan di luar pendidikan formal (Ernawati \& Mulyono, 2017). Pendidikan nonformal sebagaimana tertulis sebelumnya diketahui bahwa sebagai pelengkap pendidikan formal peran pendidikan nonformal melengkapi pendidikan formal. Hal ini dikarenakan pendidikan formal masih belum bisa meningkatkan keterampilan, pengetahuan, dan sikap untuk warga belajar. Pendidikan nonformal sebagai pengganti pendidikan formal maka pendidikan nonformal berperan menggantikan fungsi dari pendidikan formal karena pendidikan formal tidak bisa memberikan layanan pendidikan bagi warga belajar.

Pendidikan nonformal sebagai pengganti pendidikan formal dilaksanakan dalam program pendidikan nonformal yang dilaksanakan dalam institusi atau satuan pendidikan nonformal. Salah satunya adalah pendidikan bagi komunitas anak jalanan yang dilaksanakan di Klinik Jalanan Samarinda. Pada pokok permasalahan yang telah diuraikan pada pendahuluan penelitian ini diketahui bahwa anak jalanan khususnya di Kota Samarinda tidak memiliki kesempatan mengenyam pendidikan formal dikarenakan berbagai faktor diantaranya faktor ekonomi yang mengharuskan anak-anak jalanan turun ke jalan untuk bekerja. Sehingga perlu campur tangan dari pendidikan nonformal untuk mengatasi permasalahan pendidikan tersebut. 
Klinik Jalanan Samarinda hadir sebagai salah satu institusi pendidikan nonformal untuk melaksanakan kegiatan pembelajaran bagi anak jalanan di Kota Samarinda.

Kegiatan pembelajaran yang dilaksanakan untuk anak jalanan dilaksanakan di sekitar kegiatan anak jalanan itu berada sehingga fasilitator dari Klinik Jalanan mengkondisikan diri untuk mendatangi anak jalanan guna melaksanakan pembelajaran yang telah ditentukan pada setiap zona yang ditentukan oleh Klinik Jalanan Samarinda. Hal ini dikarenakan proses yang dilaksanakan pada pendidikan anak jalanan merupakan pendidikan nonformal. Pendidikan nonformal merupakan program pendidikan yang harus fleksibel, beragam dan secara fungsional terkait dengan kebutuhan dan minat peserta didik. Proses pendidikan untuk anak jalanan yang dilaksanakan oleh Klinik Jalanan bertempat di sekitar anak jalanan karena pendidikan nonformal bersifat fleksibel sehingga dapat dilaksanakan dimana dan kapan pelaksanaannya sesuai dengan kondisi dari anak jalanan itu sendiri. NFE merupakan pendidikan yang menawarkan kesempatan belajar yang dapat disesuaikan dan fleksibel dengan kebutuhan dan jadwal khusus peserta didik. Pembelajaran lebih fleksibel dari sisi waktu dan tempat sesuai dengan waktu dan tempat yang peserta, fasilitator serta tim sepakati (Kartini \& Rusman, 2019). Proses pembelajaran anak jalanan juga disesuaikan dengan kontrak belajar yang telah disepakati karena anak jalanan sendiri memiliki kesibukan disetiap harinya hal tersebut juga menuntut fasilitator dari Klinik Jalanan Samarinda untuk bisa menyesuaikan dengan kondisi anak jalanan.

\section{Evaluasi Program Pendidikan Nonformal Bagi Anak Jalanan di Klinik Jalanan Samarinda}

Proses pelaksanaan yang telah dilaksanakan oleh suatu lembaga pendidikan maka harus dinilai apakah program-program yang telah dilaksanakan sesuai dengan tujuan pelaksanaan program atau belum. Proses penilaian program dalam bahasan penelitian ini adalah proses evaluasi program. Proses evaluasi suatu program memiliki peran penting yaitu selain untuk menilai keberhasilan program, proses evaluai program ini bertujuan untuk merancang program pendidikan lanjutan. Hasil pelaksanaan evaluasi dibuktikan dengan adanya bahasan rapat mengenai perkembangan keterserapan materi bagi anak jalanan yang menjadi dasar untuk dibawa ke forum tim inti Klinik Jalanan Samarinda. Evaluasi peserta didapat dari penilaian terhadap pengetahuan, keterampilan dan sikap peserta dalam mengikuti pendidikan nonformal, dengan tujuannya adalah untuk menilai tingkat peningkatan pengetahuan, keterampilan, dan sikap peserta setelah mengikuti pendidikan nonformal (Aryanti, Supriyono \& Ishaq, 2015). Evaluasi belajar dilakukan untuk mengetahui sejauh mana daya serap peserta pelatihan terhadap materi yang diberikan dalam program serta mengetahui peningkatan pengetahuan dan skill yang diperoleh dari program (Lestari, 2018). Proses evaluasi yang dilaksanakan meliputi evaluasi pembelajaran yang dilaksanakan oleh fasilitator sebagai tenaga pengajar anak jalanan itu sendiri. Pendidik pada pendidikan nonformal adalah mereka yang mewakili kelompok profesional yang terlibat dalam evaluasi dalam konteks di mana evaluasi adalah bagian dari tanggung jawab pekerjaan mereka dan perlu diimbangi dengan tanggung jawab pekerjaan utama mereka, yaitu pengembangan dan penyampaian program pendidikan (Diaz, Chaudhary, Jayaratne \& Assan, 2020). Penyelenggaraan pelatihan sebagai pendidikan nonformal di lapangan diketahui bahwa proses evaluasi dilakukan setiap pertemuan oleh instruktur dan pendamping artinya proses pendidikan nonformal pada tahap evaluasi juga menjadi tanggung jawab pendidik atau tutor dalam kegiatan pembelajaran (Nurfaal, 2017). Evaluasi program pada kegiatan pendidikan nonformal yang dilaksanakan oleh Klinik Jalanan itu sendiri dilaksanakan untuk melihat keberhasilan program yang telah dilaksanakan. Evaluasi adalah suatu kegiatan mengumpulkan informasi yang berguna untuk mengambil keputusan dan sebagai tolak ukur sejauh mana tujuan dapat dicapai (Lazwardi, 2017). Oleh karena itu pelaksanaan evaluasi dalam pelaksanaan pendidikan nonformal penting untuk dilaksanakan. 
Selain itu juga pada evaluasi program pendidikan nonformal di Klinik Jalanan Samarinda dilakukan untuk menyusun pengembangan program pendidikan setelah program pendidikan yang dilaksanakan sebelumnya telah berhasil. Evaluasi program dimaksudkan untuk mengumpulkan, mengolah, dan menyajikan data untuk masukan dalam pengambilan keputusan mengenai program yang dilaksanakan sehingga produk dari evaluasi ini adalah diketahuinya manfaat program dan tindak lanjut dari program apakah dikembangkan atau dihentikan. Proses evaluasi dilaksanakan melalui proses evaluasi program yang dilaksanakan oleh Tim di Klinik Jalanan Samarinda bersama fasilitator pembelajaran melalui rapat untuk nantinya ditindak lanjuti bagaimana kedepannya program pembelajaran bagi anak jalanan di Klini Jalanan Samarinda. Evaluasi adalah agar mengetahui apakah setiap program berjalan dengan baik atau tidak, hal ini dapat digunakan sebagai wadah untuk mengoreksi kekurangan-kekurangan dalam setiap program dengan dilakukannya sesi tukar pikiran dan tanya jawab, dengan hal ini diharapkan program yang akan dijalankan nantinya akan berjalan lebih efektif dan produktif dengan penambahan maupun pengurangan di setiap proses pelaksanaan program (Riyanto, 2020). Proses penanganan anak jalanan dapat dilakukan dengan memberikan program pendidikan salah satunya adalah kegiatan pelatihan setelah itu melaksanakan kegiatan evaluasi yang dilakukan untuk melihat kembali semua kegiatan yang telah dilakukan untuk melihat tingkat keberhasilan, kegagalan dan juga kendala (Amin, Krisnani \& Irfan, 2014). Evaluasi bertujuan sebagai umpan balik bagi pendidik, yang pada gilirannya dapat digunakan untuk memperbaiki proses belajar (Divayana \& Sugiharni, 2016). Adanya evalusi pembelajaran pengelola dan tutor agar dapat selalu memperbaiki proses pembelajaran sehingga kualitas pembelajaran akan meningkat (Felani, 2017). Sehingga pada pelaksanaan evaluasi tim klinik jalanan dapat mengambil kebijakan pembelajaran bagi anak jalanan berdasarkan hasil evaluasi pembelajaran yang dilaksanakan.

\section{CONCLUSION}

Pendidikan nonformal yang dilaksanakan untuk anak jalanan diantaranya adalah pendidikan dasar berupa pendidikan untuk menuntaskan buta aksara meliputi kegiatan membaca, menulis, dan berhitung (calistung) sebagai pendidikan dasar bagi anak jalanan. Selain itu pendidikan keterampilan hidup untuk membekali anak jalanan keterampilan yang dapat digunakan untuk mengembangkan kapasitasnya sehinga dari adanya pendidikan keterampilan ini dapat menjadikan anak jalanan memiliki kapasitas sehingga anak jalanan tidak kembali lagi ke jalan.

\section{REFERENCES}

Amin, M. A., Krisnani, H. H., \& Irfan, M. (2014). Pelayanan Sosial Bagi Anak Jalanan Ditinjau Dari Perspektif Pekerjaan Sosial. Share Social Work Jurnal, 4(2), 181-189. https://doi.org//10.24198/share.v4i2.13079.

Anandar, R., Wibhawa, B., \& Wibowo, H. (2015). Dukungan Sosial Terhadap Anak Jalanan Di Rumah. Share Social Work Jurnal, 5(1), 81-88. https://doi.org//10.24198/share.v5i1.13122.

Anandar, R., \& Wibowo, H. (2015). Model Pendekatan Centre Based Dalam Menangani Anak Jalanan Perempuan. Share Social Work Jurnal, 5(2), 106-208. https://doi.org//10.24198/share.v5i2.13139.

Arnady, M. A., \& Prasetyo, I. (2016). Evaluasi program kecakapan hidup di sanggar kegiatan belajar Bantul, Yogyakarta. Jurnal Pendidikan Dan Pemberdayaan Masyarakat, 3(1), 60-74. https://doi.org/10.21831/jppm.v3i1.6303. 
Aryanti, T., Supriyono, \& Ishaq M. (2015). Evaluasi Program Pendidikan Dan Pelatihan. Jurnal Pendidikan Nonform, 10(5), 1-13.

Dani, R. P., Mundzir, M., \& Hardika, H. (2018). Pendidikan Luar Sekolah dalam Perspektif Purna Tenaga Kerja Indonesia (Studi Fenomenologi Di Pagelaran Malang). Jurnal Pendidikan Nonformal, 10(1), 25-35.

Diaz, J., Chaudhary, A. K., Jayaratne, K. S. U., \& Assan, E. (2020). Expanding evaluator competency research: Exploring competencies for program evaluation using the context of non-formal education. Evaluation and Program Planning, 79(February), 101790. https://doi.org/10.1016/j.evalprogplan.2020.101790.

Divayana, D. G. H., \& Sugiharni, G. A. D. (2016). Evaluasi Program Sertifikasi Komputer Pada Universitas Teknologi Indonesia Menggunakan Model Cse-Ucla. JPI (Jurnal Pendidikan Indonesia), 5(2), 158. https://doi.org/10.23887/jpi-undiksha.v5i2.8586.

Elian, A. F., \& Ilyas, I. (2020). Pelaksanaan Metode Pembelajaran Partisipatif Pada Kursus Mahacoustic Music Management Di Kota Semarang. Aksara: Jurnal Ilmu Pendidikan Nonformal, 6(2), 111. https://doi.org/10.37905/aksara.6.2.111-120.2020.

Ernawati, \& Mulyono, S. E. (2017). Manajemen Pembelajaran Program Paket C Di PKBM Bangkit Kota Semarang. Journal of Nonformal Education, 3(1), 60-71. https://doi.org/10.15294/jne.v3i1.8915.

Felani, N. (2017). Implementasi Pembelajaran PKBM Berbasis Budaya Guna Mendukung Pelestarian Budaya DI PKBM Wiratama Yogyakarta. Diklus: Jurnal Pendidikan Luar Sekolah, 1(1), 52-62. https://doi.org/10.21831/diklus.v1i1.23852.

Herlina, A. (2014). Kehidupan anak jalanan di Indonesia : faktor penyebab, tatanan hidup dan kerentanan berperilaku menyimpang. Pusat Pengkajian, Pengolahan Data Dan Informasi (P3DI) Sekretariat, 5(2), 145-155.

Hermawan, Y., \& Suryono, Y. (2016). Partisipasi Masyarakat Dalam Penyelenggaraan Program-Program Pusat Kegiatan Belajar Masyarakat Ngudi Kapinteran. JPPM (Jurnal Pendidikan Dan Pemberdayaan Masyarakat), 3(1), 97-108. https://doi.org/https://doi.org/10.21831/jppm.v3i1.8111.

Kartini, T., \& Rusman, R. (2019). Studi Evaluatif Kurikulum Diklat Berjenjang Tingkat Dasar Dalam Jaringan Terhadap Peningkatan Kompetensi Pendidik Paud. Diklus: Jurnal Pendidikan Luar Sekolah, 2(2), 74-86. https://doi.org/10.21831/diklus.v2i2.23651.

Kolawole, O. D., \& Pusoetsile, T. (2021). What difference does literacy make among adult learners? Impact of adult basic education programme in a rural community in Botswana. Journal of Adult and Continuing Education, 147797142110074. https://doi.org/10.1177/14779714211007495.

Lazwardi, D. (2017). Implementasi Evaluasi Program Pendidikan Di Tingkat Sekolah Dasar Dan Menengah. Kependidikan Islam, 7(2), 67-79.

Lestari, W. E. W. (2018). Evaluasi Program Kursus Office Terpadu Di Lembaga Kursus Dan Pelatihan (LKP) Bimantara Klaten. Diklus: Jurnal Pendidikan Luar Sekolah, 2(1), 5361.

Masdin, M., \& Mulu, B. (2017). Anak Jalanan Di Kota Kendari Menuju Kota Layak Anak. AlIzzah: Jurnal Hasil-Hasil Penelitian, 12(2), 100-111. https://doi.org/10.31332/ai.v12i2.643.

Melindra, Y., \& Irmawita. (2020). Documentation Study Of Street Children By Social Office Of Padang City. Spektrum: Jurnal Pendidikan Luar Sekolah, 8(2), 175-181. https://doi.org/10.24036/spektrumpls.v8i2.109221.

Muslim, A. Q., \& Suci, I. G. S. (2020). Peran Manajemen Pendidikan Nonformal Berbasis Masyarakat Sebagai Upaya Peningkata Sumber Daya Manusia Di Indonesia. Pratama Widya: Jurnal Pendidikan Anak Usia Dini, 5(2), 159-168. 
Nurfaal, A. R. (2017). Penyelenggaraan Program Pelatihan Tata Busana Di Balai Perlindungan Dan Rehabilitasi Sosial Wanita (BPRSW) Daerah Istimewa Yogyakarta (DIY). Diklus: Jurnal Pendidikan Luar Sekolah, 1(1), 107-118. https://doi.org//10.21831/diklus.v1i1.23860.

Olomukoro, C. O., \& Adelore, O. O. (2015). Political Empowerment of Women through Literacy Education Programmes in EDO and Delta States, Nigeria. Journal of Adult and Continuing Education, 21(2), 3-23. https://doi.org/10.7227/jace.21.2.2.

Riyanto, P. (2020). Literasi sebagai Upaya Penanaman Karakter Peduli Lingkungan melalui. DIKLUS: Jurnal Pendidikan Luar Sekolah, 4(1), 45-54. https://doi.org//10.21831/diklus.v4i1.27889.

Rizka, M. A., \& Hardiansyah, R. (2016). Strategi pengembangan inovasi program pendidikan nonformal sebagai best practices bagi pusat kegiatan belajar masyarakat. Jurnal $\begin{array}{llll}\text { Pendidikan Dan Pemberdayaan } & \text { Masyarakat, }\end{array}$ https://doi.org/10.21831/jppm.v3i2.10745.

Rochimah, N. A. (2016). Pengelolaan Layanan Pembelajaran Anak Jalanan Di Lembaga PPAP Seroja Surakarta. Jurnal Pendidikan Ilmu Sosial, 26(1).

Safitri, D. N. (2017). Pendidikan Nonformal Untuk Meningkatkan Kemampuan Dan Kemandirian Siswa Di Desa Kunci. J-ABDIPAMAS: Jurnal Pengabdian Kepada Masyarakat, 1(1), 1. https://doi.org/10.30734/j-abdipamas.v1i1.59.

Setiawan, E. G., Wahyudi, C., \& Jatmikowati, S. H. (2016). Pembinaan Anak Jalanan Melalui Home Shelter "Griya Baca" Kota Malang Sebagai Upaya Menuju Kota Layak Anak. Publisia Jurnal Ilmu Administrasi Publik, 1(1), 24-37. https://jurnal.unmer.ac.id/index.php/jkpp/article/view/425/198.

Sugiyono. (2016). Metode Penelitian Kualitatif, Kuantitatif, dan R\&D. Alfabeta.

Sukmaningrum, P. S., \& Faizah, S. I. (2019). Strategi Penguatan Ekonomi Orang Tua pada Keluarga Anak Jalanan di Surabaya. Jurnal Sosial Humaniora, 12(2), 66. https://doi.org/10.12962/j24433527.v12i2.4209.

Ummatin, K. (2020). Kebijakan Proteksi Anak Jalanan di Kota Yogyakarta Menurut Perspektif Maqasid Syariah. Ulul Albab: Jurnal Studi Dan Penelitian Hukum Islam, 3(1), 1. https://doi.org/10.30659/jua.v3i1.4987. 